\title{
Techno-economic feasibility of power to gas-oxy-fuel boiler hybrid system under uncertainty
}

\author{
Manuel Bailera ${ }^{a}$, Dawid P. Hanak ${ }^{b}$, Pilar Lisbona ${ }^{c}$, Luis M. Romeo ${ }^{a, *}$ \\ a Escuela de Ingeniería y Arquitectura, Universidad de Zaragoza, Campus Río Ebro, María de Luna 3, 50018, \\ Zaragoza, Spain \\ ${ }^{\mathrm{b}}$ Clean Power Engineering, Cranfield University, Bedford, Bedfordshire, MK43 OAL, United Kingdom \\ ${ }^{\mathrm{c}}$ Escuela de Ingeniería de la Industria Forestal, Agronómica y de la Bioenergía, Universidad de Valladolid, \\ Campus Universitario Duques de Soria, 42004, Soria, Spain
}

\section{A R T I C L E I N F O}

Article history:

Received 12 May 2018

Received in revised form

7 September 2018

Accepted 17 September 2018

Available online $\mathrm{xxx}$

\section{Keywords:}

Power-to-gas

Energy storage

Uncertainty

Probabilistic analysis

Process modelling and simulation

Techno-economic analysis

\begin{abstract}
A B S T R A C T
One of the main challenges associated with utilisation of the renewable energy is the need for energy storage to handle its intermittent nature. Power-to-Gas (PtG) represents a promising option to foster the conversion of renewable electricity into energy carriers that may attend electrical, thermal, or mechanical needs on-demand. This work aimed to incorporate a stochastic approach (Artificial Neural Network combined with Monte Carlo simulations) into the thermodynamic and economic analysis of the PtG process hybridized with an oxy-fuel boiler (modelled in Aspen Plus ${ }^{\circledR}$ ). Such approach generated probability density curves for the key techno-economic performance indicators of the PtG process. Results showed that the mean utilisation of electricity from RES, accounting for the chemical energy in SNG and heat from methanators, reached $62.6 \%$. Besides, the probability that the discounted cash flow is positive was estimated to be only $13.4 \%$, under the set of conditions considered in the work. This work also showed that in order to make the mean net present value positive, subsidies of $68 € / \mathrm{MW}_{\mathrm{el}} \mathrm{h}$ are required (with respect to the electricity consumed by PtG process from RES). This figure is similar to the financial aids received by other technologies in the current economic environment.
\end{abstract}

(C) 2018 Hydrogen Energy Publications LLC. Published by Elsevier Ltd. All rights reserved.

\section{Introduction}

The current European energy policy was established in 2009 through the European Renewable Energy Directive (RED 2009/ $28 / \mathrm{EC}$ ) [1], which sets a minimum of $20 \%$ of renewable share in the European final energy consumption by 2020 and a $10 \%$ of renewable penetration in the transport sector. The European
Commission updated these figures in November 2016 with a new proposal to ensure $27 \%$ renewables in the final energy consumption in the EU by 2030 [2].

Each country is obligated to fulfil its individual emissions reduction target that has been adapted to their different resources and the features of its own energy market. In 2013/ 2014, all Member States, but the Netherlands, showed an average share of renewable energy sources (RES) equal or

Abbreviations: ASU, air separation unit; HES, hydrogen energy storage; LHV, lower heating value; PtG, power-to-gas; RED, renewable energy directive; RES, renewable energy sources.

* Corresponding author.

E-mail address: luismi@unizar.es (L.M. Romeo).

0360-3199/@ 2018 Hydrogen Energy Publications LLC. Published by Elsevier Ltd. All rights reserved. 
higher than their corresponding indicative trajectory set out by the European Directive. In 2015, European RES share was estimated to be around $16.4 \%$ of the gross final energy consumption, while the Directive had projected only $13.8 \%$. Larger penetration of RES will be required in the next decades to achieve the global emissions reduction target (20\% in 2020 or $27 \%$ in 2030) and further work must be done to increase the current share of biofuels in the transport sector $(0.5 \%)$ to meet the Directive target.

The high share of RES in the electricity production system will lead to fluctuating periods of surplus power that could limit the operational predictability and flexibility of the electricity network [3]. Thus, energy storage technologies are imperative in future electricity systems to manage intermittent renewable energy [4,5]. Current energy storage techniques (pumped hydroelectric storage, compressed air energy storage, flywheels, electrochemical storage, thermal energy storage) present limited potentials for large scale applications due to special location requirements, short storage periods, slow discharge times or low energy storage densities [3]. Hydrogen energy storage (HES) overcomes these issues, but it lacks a proper distribution infrastructure and transformation technology. Besides, HES implies additional handling safety measures. To avoid the mentioned limitations, Power-to-Gas (PtG) energy storage, which combines HES and methanation to convert mixtures of renewable $\mathrm{H}_{2}$ and $\mathrm{CO}_{2}$ into synthetic natural gas (SNG), has been shown as a very promising solution in the last years [6,7]. This final energy carrier can be easily stored and distributed through the existing gas grid and transformed into electricity or heat in the conventional equipment that is characterised with high efficiency, durability and limited investment costs (Fig. 1).

The conversion of electricity in the PtG system is carried out by an electrolyser which produces hydrogen. The consumption of the generated hydrogen through the Sabatier chemical reaction produces methane and thus SNG is obtained. The global chemical process is carried out through two consecutive reactions: inverse water-gas shift reaction and $\mathrm{CO}$ methanation. The inverse water-gas shift reaction is endothermic and requires the presence of a catalyst. CO methanation takes place always promoted by inverse water-gas shift reaction.

Different hybridization options of the PtG system with biogas plants, biomass gasification, sewage plants, fossil power plants or industrial processes as the source of $\mathrm{CO}_{2}$ have been proposed [8]. One interesting option for these processes is the utilisation of the residual oxygen produced by electrolysis in an oxy-fuel boiler that directly produces a concentrated stream of $\mathrm{CO}_{2}$. During oxy-fuel combustion, pure oxygen is used as comburent instead of air [9]. Thus, the large $\mathrm{N}_{2}$ content in air is substituted by the combustion products (mainly $\mathrm{CO}_{2}$ and $\mathrm{H}_{2} \mathrm{O}$ ), and flue gas can achieve a high $\mathrm{CO}_{2}$ concentration once water vapour is condensed and removed. In the oxy-fuel combustion, the energy penalty mainly comes from the air separation unit (ASU) that produces the required oxygen (typically $190 \mathrm{kWh} / \mathrm{tO}_{2}$ ) [10]. Therefore, by using the oxygen from electrolysis, the electrical consumption of the ASU would be suppressed. Furthermore, if $\mathrm{CO}_{2}$ is recycled to SNG in a closed loop (i.e., SNG generated is used in the same or another PtG-carbon capture system), the energy consumption related to the permanent sequestration of $\mathrm{CO}_{2}$

\section{Electricity network}

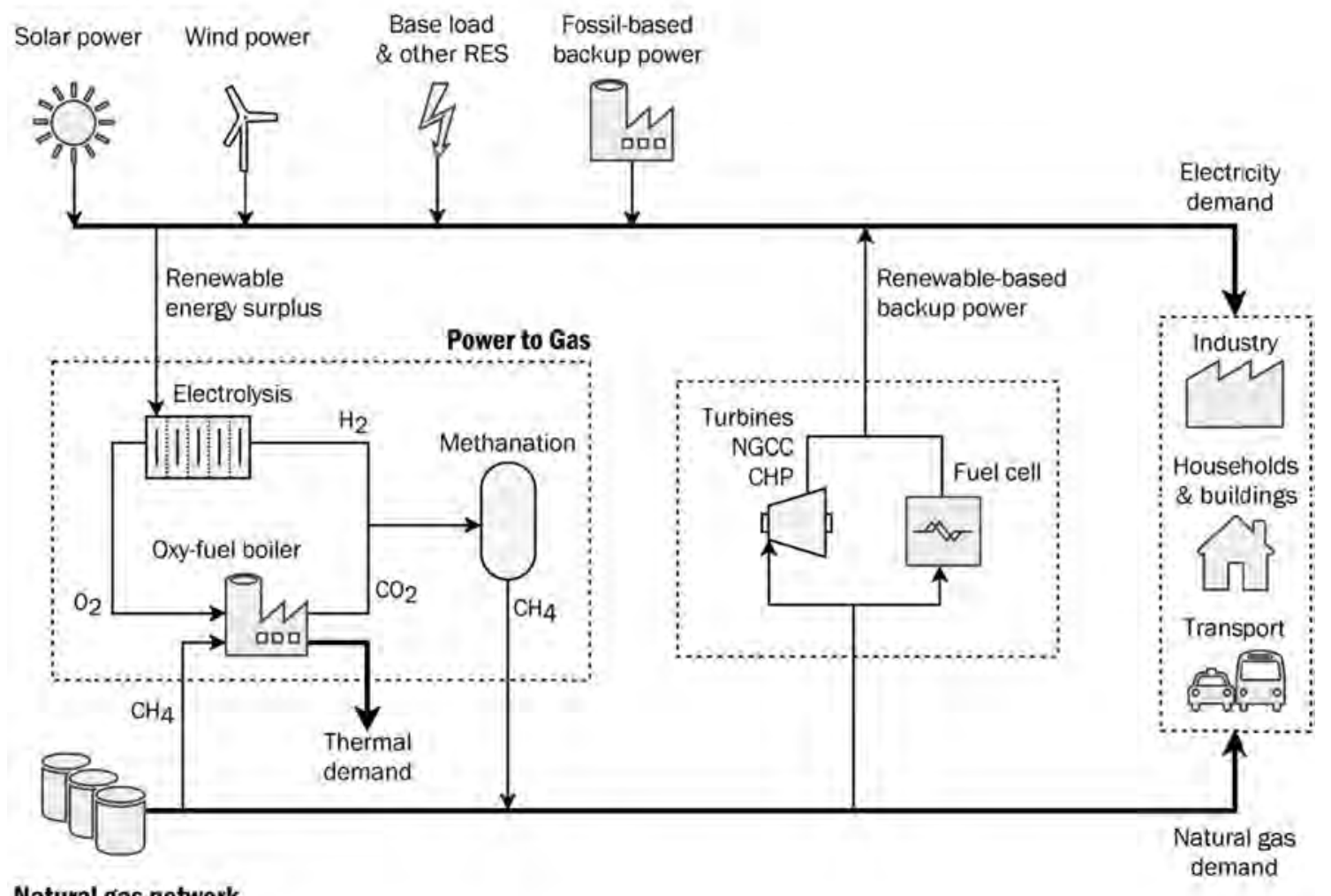

Fig. 1 - Scheme of the energy system with PtG-oxy-fuel boiler. 
(compression, transport and underground storage) would be avoided, since such sequestration process would be postponed indefinitely. This hybridization dramatically reduces the consumption of energy to attain a concentrated stream of $\mathrm{CO}_{2}$ required in the methanation step since there is no need of a further stage of separation.

The economics of the PtG systems has been recently analysed $[6,11]$ and some simplified methodologies for determining the price ratio of the electric energy sales to the purchase price of the electricity to make the $\mathrm{H}_{2}$ production technology applied to PtG economically attractive have been recently presented [12]. Some works have included both a techno-economic [13] and a life cycle assessment to determine the performance, levelised cost and value of PtG plants purchasing electricity and selling SNG to the market, depending on the system configuration under a specific regulatory context [14]. Probabilistic optimal power flow models have also been used to simulate the operation of coupled electric power and natural gas systems multiple periods to avoid overly-optimistic solutions in the design [15]. Other similar works have also considered the natural gas, heat, and power demand balances using deterministic models to wind power and the PtG system [16].

However, the economic results predicted for the deployment of the PtG technologies in the energy mix have been obtained through deterministic models. A deterministic approach can provide useful information under any set of assumptions, but these models do not take into account the uncertainty of the input variables and are very sensitive to the selection of specific assumptions. The inputs of the technoeconomic models such as efficiencies of the equipment, RES availability, investment costs, electricity and methane prices can vary significantly depending on the considered environment. Thus, the deterministic nature of such model predictions does not provide a final representation of real economic performance [17] that may lead to cost overruns, as reported for around $40 \%$ of the mega-projects across different industries [18]. For this reason, the credibility of economic model prediction can be improved by taking into account the uncertainties in the model inputs to formulate the estimations of the most advantageous and less advantageous scenarios, as well as the probabilistic distributions of the economic model outputs.

A stochastic analysis, which comprises a set of analytical tools that systematically consider uncertainty impact on the key performance indicators [16,19], have been applied to techno-economic assessments of engineering systems to provide a profound insight into their operation and performance [19], to calculate the effect on levelized cost of electricity $[20,21]$ or to analyse $\mathrm{CO}_{2}$ capture and storage systems [22-24]. Consideration of the uncertainty in the operating conditions at the process design stage can reduce the occurrence of the failures associated with vibration stresses and unstable operation [25-27], equipment overheating [25], and other failures associated with poor design and increased complexity [28]. By indicating the probabilities of possible outcomes, a stochastic approach to evaluation of the process performance provides a more profound insight into the investment decision-making process and may potentially lead to a different outcomes compared to the deterministic approach [24].
As indicated above, the economic performance of the PtG facilities has only been assessed using deterministic models that do not consider uncertainties in the input variables. For this reason, this work employs the stochastic analysis for the techno-economic performance of the PtG process. This aims to highlight that the development of improved energy storage technologies is especially relevant to exploit the greatest amount of the renewable potential without introducing instabilities in the future renewable electric system.

In this work, a robust approximation model of the PtG process using Artificial Neural Network (ANN), which is inspired by the structure of biological neural networks and the process they utilise to solve problems [29], is combined with Monte Carlo simulations to generate probability density curves for the key techno-economic performance indicators of the PtG process. In contrast to the conventional approximation models, ANN learns the relations between the inputs and outputs by training [30]. It has been shown to be an accurate approximation model for systems with multiple inputs and outputs [31], even for highly nonlinear systems $[30,32]$. It has also been shown to perform better than generic quadratic multi-variable polynomial model in approximation of nonlinear energy systems [24]. Data required to the construction of the ANN are derived from a large number of deterministic simulations in Aspen Plus ${ }^{\circledR}$. Considering the effect of uncertainties on the prediction of key economic indicators, the obtained analysis will contribute to a deeper understanding of economic feasibility of the considered energy storage systems.

\section{PtG-oxy-fuel boiler model description}

The analyses of the combined system PtG and oxy-fuel boiler with thermal purposes was first proposed by Bailera et al. $[7,33]$. The assumptions of the deterministic model and definition of efficiencies of the single elements and the hybrid concept presented in these studies are also applied in this model. The input data to the Aspen Plus ${ }^{\circledR}$ model, as well as the chosen calculation methods, are also described in the following. Fig. 2 illustrates the schematic diagram of the hybrid concept where the main streams are identified.

The RES power the electrolyser which allows storing this renewable energy as hydrogen also producing oxygen as a byproduct. Under specific conditions, this amount of oxygen may completely cover the comburent demand in the oxy-fuel

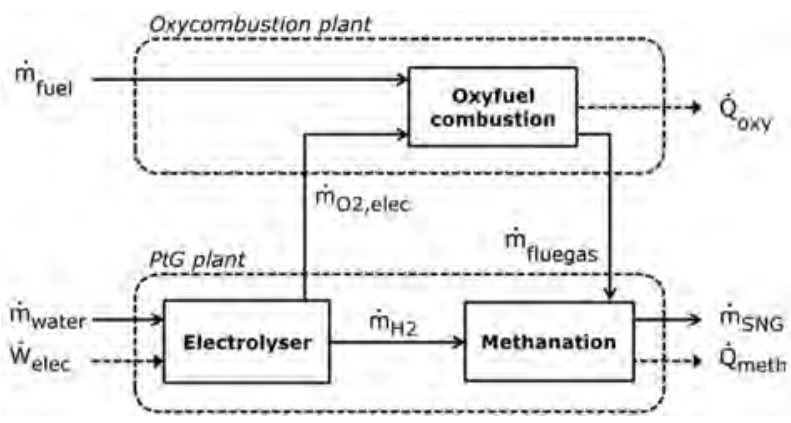

Fig. 2 - Schematic diagram of the proposed oxy-power-togas hybrid concept. 
boiler. This hybridization increases the efficiency of the oxycombustion process through the avoidance of the air separation unit consumption. Methanation takes place between the flue gas from the oxy-fuel thermal plant and the hydrogen from electrolysis to produce SNG. Heat is recovered from the oxy-fuel boiler and from the exothermic reaction in methanators. This extra available heat could be integrated in external thermal processes or in the hybrid concept itself and would lead to higher thermal efficiencies. Besides, as fuel and SNG are consumed/produced in the same amount, it is assumed that $\mathrm{CO}_{2}$ is used as an energy carrier that is continuously recycled to SNG using renewable electricity. Thus, variable renewable energy sources are converted to thermal sources on-demand.

The proposed scheme for the hybridization between oxycombustion and PtG technologies has been modelled in Aspen Plus $^{\circledR}$ under industrial conditions for steady state operation and chemical equilibrium. Natural gas is selected to fuel the combustion process. The deterministic model of each significant component of the system is presented below.

\section{Oxy-fuel combustion boiler}

SNG, which comes from the methanation stage, and comburent are introduced into the boiler to reach chemical equilibrium by minimizing Gibbs free energy. Flue gas passes through the heat exchangers where steam is produced reducing its temperature down to $270{ }^{\circ} \mathrm{C}$. This energy corresponds to the useful thermal power output of the oxy-fuel boiler. Flue gas is then cooled down, while the comburent is preheated to around $150{ }^{\circ} \mathrm{C} .80 \%$ of flue gas is then recirculated to the boiler to control temperature. A condensation stage is located prior comburent mixing for oxy-fuel applications to avoid accumulation of large amounts of water. The comburent is composed of oxygen from the electrolyser and preheated recirculated flue gas. The oxygen excess in the boiler is set as $15 \%$. There is no need of air separation unit module.

\section{Electrolyser}

Power from a renewable source is modelled as an energy input to the electrolyser module. The amount of produced hydrogen will be modified depending on the provided energy that will then affect the percentage of flue gas directed to the PtG process, the flow of generated SNG, and the global hybrid system operation efficiency.

Alkaline electrolyser has been modelled by programming a user-defined subroutine in Aspen Plus ${ }^{\circledR}$. The inlet power and water stream are the input variables for the external calculations. This block splits water in two mass flows of pure oxygen and a mixture of hydrogen with unreacted water. Water conversion is assumed to be $99.9 \%$ with an electrical consumption range from 4.3 to $4.9 \mathrm{kWh} / \mathrm{Nm}^{3} \mathrm{H}_{2}$ and an outlet temperature of $80^{\circ} \mathrm{C}$ [34]. These operation conditions leads to an efficiency range of the electrolyser unit, $\eta_{\mathrm{LHV}}=61.2-69.7 \%$.

\section{Methanation stage}

The methanation process considered in this work is based on two isothermal reactors at 30 bar with an intermediate condensation stage. It uses high temperature catalysts $\left(250-550^{\circ} \mathrm{C}\right)$ to recover the high-grade heat as high pressure steam [35]. The main target of the methanation process is to achieve methane molar fractions above $95 \%$ in SNG so that it has similar characteristics that the natural gas from the network, and therefore conventional equipment for natural gas can be used.

The reactor blocks calculate the composition and temperature of the outlet gaseous streams, at equilibrium state, minimizing Gibbs free energy in an isothermal process. The flue gas flow from oxy-fuel combustion directed to methanation process is determined by the electrical power consumption in electrolyser, as well as the $\mathrm{CO}_{2}$ and $\mathrm{O}_{2}$ concentration in flue gas. A constant $\mathrm{H}_{2}: \mathrm{CO}_{2}$ molar ratio of 4 has been set at the inlet of the first reactor.

SNG is cooled from $395^{\circ} \mathrm{C}$ in the Reactor 1 to $260^{\circ} \mathrm{C}$ and the recovered heat is used to produce steam. It is further cooled to $135{ }^{\circ} \mathrm{C}$ and water vapour is partially condensed to avoid the inhibition the methanation reaction. Before Reactor 2, the gas is heated to $300^{\circ} \mathrm{C}$ using heat form isothermal Reactor 1 . The final outlet stream is cooled down to $40{ }^{\circ} \mathrm{C}$ to condense water vapour and reach a purity of methane over $95 \%$.

\section{Methodology of uncertainty analysis}

\section{Deterministic assessment methodology}

The thermodynamic performance of the PtG process is assessed by estimating a number of partial efficiencies, including the energy storage efficiency defined in Eq. (1), which considers the lower heating value $\left(\mathrm{LHV}_{\mathrm{SNG}}\right)$ and mass flow of the produced syngas $\left(m_{S N G}\right)$, the efficiency of heat production in the oxy-fuel boiler $\left(Q_{1}\right)$ defined in Eq. (2), the efficiency of the heat recovery in the methanation stage $\left(Q_{2}\right)$ defined in Eq. (3), and the overall thermal efficiency of the entire PtG-oxy-fuel process given in Eq. (4). Importantly, these partial efficiencies were calculated with respect to the electricity input from RES to reflect the relative conversion of RES to useful products in the PtG process.

$$
\begin{aligned}
& \eta_{\text {storage }}=\frac{L H V_{S N G} \dot{m}_{S N G}}{\dot{\mathrm{W}}_{\text {elec }}} \\
& \eta_{\text {production }}=\frac{\dot{\mathrm{Q}}_{1}}{\dot{\mathrm{W}}_{\text {elec }}} \\
& \eta_{\text {recovery }}=\frac{\dot{\mathrm{Q}}_{2}}{\dot{\mathrm{W}}_{\text {elec }}} \\
& \eta_{\text {thermal }}=\frac{\dot{\mathrm{Q}}_{1}+\dot{\mathrm{Q}}_{2}}{\dot{\mathrm{W}}_{\text {elec }}}
\end{aligned}
$$

The economic performance of the PtG process is assessed utilizing the net present value (NPV) approach that is commonly applied in assessment of engineering systems $[13,36,37]$. The NPV can be defined in Eq. (5) as the difference between the capital investment per unit renewable electricity input $\left(R_{0}\right)$ and the sum of discounted net cash flows $\left(R_{t}\right)$ that considers discount rate $(i)$ and the project lifetime $(N)$. 
$N P V=-R_{0}+\sum_{t=1}^{N} \frac{R_{t}}{(1+i)^{t}}$

The capital investment related to the entire PtG-oxy-fuel process $\left(R_{0}\right)$ is assumed to be between 0.8 and $2.0 \mathrm{M} € / \mathrm{MW}$ el according to the figures reported in the literature [38,39]. The net cash flow is calculated as the difference between the annual revenue and expenditure per unit renewable electricity input using Eq. (6), considering the annual PtG process operating time $(h)$. This includes:

- the revenue from sales of heat, which stem from heat production $\left(Q_{1}\right)$ and heat recovery $\left(Q_{2}\right)$, at a price $C_{Q}$;

- the expenditure from the electricity consumption from RES at a price $C_{R E}$; and

- the operating and maintenance expenditure of $2 \%$ of the capital investment [39].

$R_{t}=\left(\frac{C_{Q}}{10^{6}} \cdot \eta_{\text {thermal }} \cdot h\right)-\left(\frac{C_{R E}}{10^{6}} \cdot h+0.02 \cdot R_{0}\right)$

\section{Stochastic assessment methodology}

To account for the uncertainty in the input variables to the techno-economic models, the stochastic approach is implemented by following the procedure presented in Fig. 3 and described in detail elsewhere [22,24]. First, the PtG process model was developed in Aspen Plus ${ }^{\circledR}$ and the corresponding economic model was built in MS Excel, as detailed in Section Deterministic assessment methodology. Second, the stochastic variables in techno-economic models, along with their statistical representation, were identified. Third, the PtG process model is much more computationally demanding than the economic model, and therefore, is not directly applicable in the stochastic analysis. To achieve a robust representation of the $\mathrm{PtG}$ process, a non-intrusive formulation based on the stochastic response surface method [40] was used that represent the relationship between the model input and output variables. A wide number of approximation models is available for robust and accurate representation of the considered model, such as polynomial regression and surrogate models [41,42] and artificial neural network (ANN) [24]. Such an approximation model developed based on the design matrix, which comprises a wide operating envelope of the PtG process and was generated using Aspen Plus ${ }^{\circledR}$ model. This study employed the ANN to approximate the PtG process, as it has been shown to better represent the nonlinear systems [21]. The ANN model and the economic model were then integrated in MS Excel. These were finally used in the stochastic analysis that employs the Monte Carlo simulations to randomly generate the input dataset in ten thousand iterations. This generated the probability density curves for the key techno-economic performance indicators of the PtG process.

\section{Identification of stochastic variables}

The stochastic input variables in the techno-economic model for the PtG process can be divided into the process and economic variables (Table 1). The thermodynamic performance of the PtG process is directly dependent upon a number of efficiencies characterising its particular components, including efficiency of the electrolyser and efficiency of the boiler. These directly affect the ratio of the energy contained in the syngas produced in the PtG process and RES input, which is defined as energy storage efficiency, the amount of

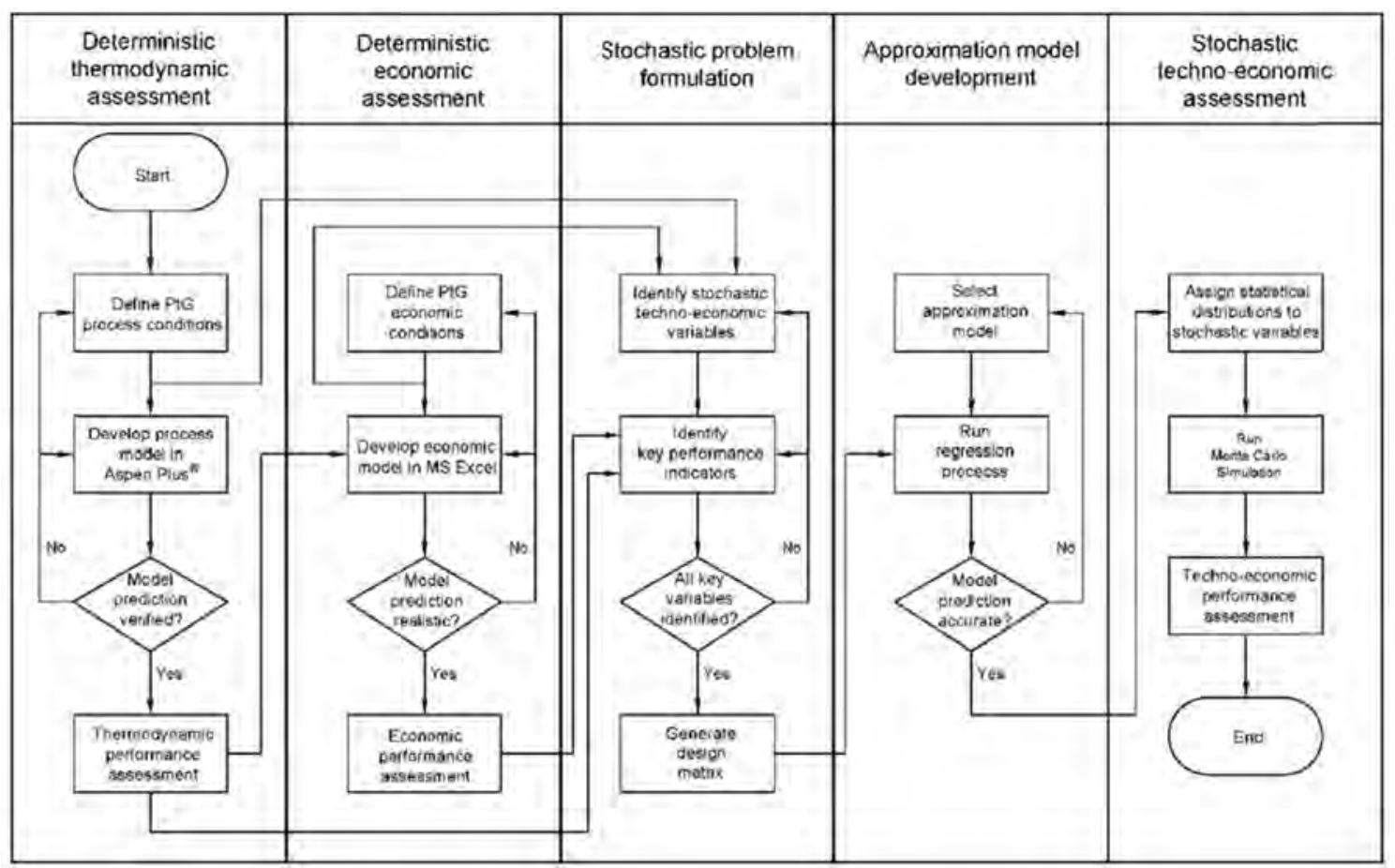

Fig. 3 - Swim lane diagram for the stochastic techno-economic assessment framework. 
Table 1 - Stochastic variables and their distribution.

\begin{tabular}{|c|c|c|c|c|}
\hline Variable & Distribution & Nominal value & Variation $^{a}$ & Reference \\
\hline \multicolumn{5}{|l|}{ Process variables } \\
\hline Efficiency of the electrolyser (\%) & Normal & 65 & 2 & [6] \\
\hline Efficiency of the boiler (\%) & Normal & 88 & 2 & [7] \\
\hline \multirow{2}{*}{\multicolumn{5}{|c|}{ Economic variables }} \\
\hline & & & & \\
\hline Cost of electricity $\left(€ / \mathrm{MW}_{\mathrm{el}} \mathrm{h}\right)$ & Uniform & 0 & $0-25$ & [44] \\
\hline Price of heat $\left(€ / \mathrm{MW}_{\mathrm{th}} \mathrm{h}\right)$ & Uniform & 40 & $20-40$ & [45] \\
\hline Specific capital investment $\left(\mathrm{M} € / \mathrm{MW}_{\mathrm{el}}\right)$ & Normal & 1.5 & 0.1 & {$[38,39]$} \\
\hline Operating time $(\mathrm{h})$ & Normal & 2190 & 438 & [39] \\
\hline Project lifetime (year) & Uniform & 25 & $15-25$ & [8] \\
\hline Discount rate (\%) & Uniform & 8.8 & $8-12$ & [13] \\
\hline
\end{tabular}

heat produced in the oxy-fuel boiler and recovered from the methanation stage, hence the overall thermal efficiency of the PtG process. These input variables are assumed to be normally distributed. Moreover, the methane content in SNG is used as a design target in the methanation stage and impacts the thermodynamic performance of the PtG process, but to a smaller extent compared to the efficiencies of the process components. As this is a design target, it is assumed to have a uniform distribution.

Although the PtG-oxy-fuel system was simulated in steady state, partial load performance and different RES profiles can be assumed to be accounted within the distribution functions of the efficiencies in Table 1 . In practice, the operating time reported in Table 1 , which stands for equivalent operating hours at nominal load, will take place during a larger number of hours at different partial loads. In a year-round operation, the system would have an overall performance lower than the nominal efficiency due to the partial load periods. Thus, those values of lower efficiencies would describe operations with a great number of operating hours at partial load, while the higher efficiencies accounts for operations with a greater number of operating hours at nominal load.

The economic performance of the PtG process is dependent upon economic variables related to the cost of electricity and the price of heat, which determine the operating expenditure and revenue, respectively, capital investment, and the project characteristics, including operating time, project lifetime and discount rate. Most of these variables are assumed to have a uniform distribution, with exception of specific capital investment and operating time for which normal distributions were assumed. As the amount of SNG that is consumed in the oxy-fuel boiler is the same that is later produced in the methanation stage, both cost and revenue of SNG are considered to cancel each other, and therefore not included as stochastic variables.

\section{Stochastic response surface approximation model using artificial neural network}

As indicated above, the PtG process model developed in Aspen Plus ${ }^{\circledR}$ cannot be directly used in the stochastic analysis, as it is much more computationally demanding compared to the economic model. This will lead to a high computational demand in the Monte Carlo simulation. Therefore, the design matrix was generated using the Aspen Plus ${ }^{\circledR}$ model and used to develop a robust approximation model that comprehensively maps the PtG process operating envelope. The design matrix comprises of 64 entries of process input parameters required in the techno-economic analysis that were generated from the following variation of the stochastic process variables:

- Efficiency of the electrolyser was varied between 60 and $75 \%$;

- Efficiency of the oxy-fuel boiler was varied between 80 and 95\%;

- Methane content in the SNG was varied between 80 and $95 \%$.

To accurately represent the PtG process, ANN was developed using the MATLAB Neural Network Fitting toolbox. In this study, a two-layer feedforward ANN with ten sigmoid hidden neurons and linear output neurons (Fig. 4) has been developed based on the design matrix generated using Aspen Plus ${ }^{\circledR}$ to link the process inputs to the process model with the process inputs to the economic model. The number of hidden neurons was selected to be higher than the number of the ANN output parameters to ensure high accuracy. In addition, the input data were randomly divided between training (70\%), validation (15\%), and testing (15\%) samples. The weights and bias in the ANN have been optimised using the Levenberg-Marquardt backpropagation algorithm with Bayesian regularisation, as it is expected to result in good representation of nonlinear and small datasets. The prediction of the ANN model was compared with the PtG process model in Aspen Plus ${ }^{\circledR}$ and the resulting discrepancy was found to be less than $1 \%$ for all output parameters. Hence, it was regarded as capable of accurately representing the design matrix and was used in the stochastic techno-economic assessment (see Fig. 5).

\section{Results of stochastic techno-economic feasibility assessment}

\section{Thermodynamic performance}

As indicated above, the key thermodynamic performance indicators for the PtG process are mainly related to the storage efficiency, heat production efficiency, overall efficiency, and avoided $\mathrm{CO}_{2}$ per unit of heat production. The stochastic analysis 


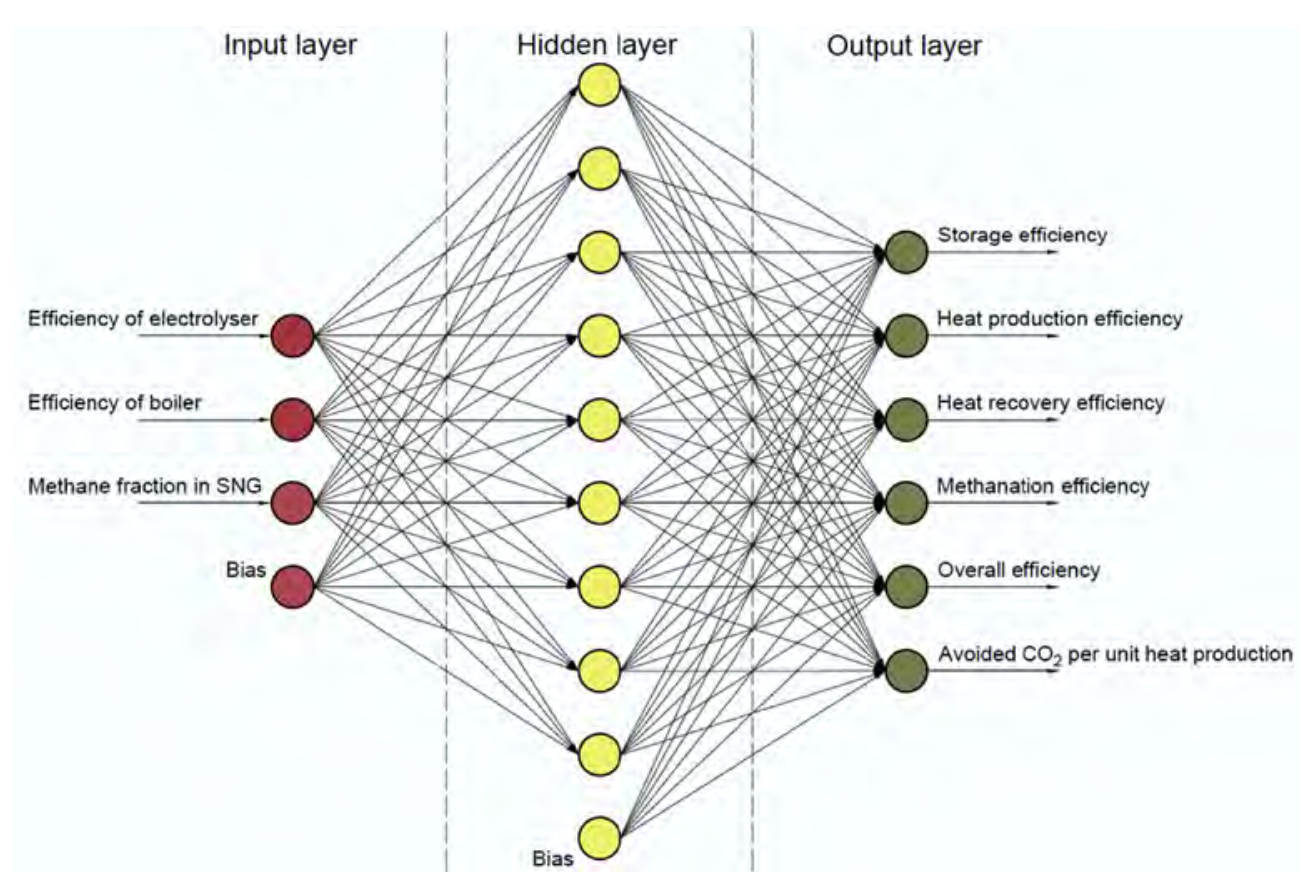

Fig. 4 - Structure of the artificial neural network used to map the thermodynamic performance of the PtG process.

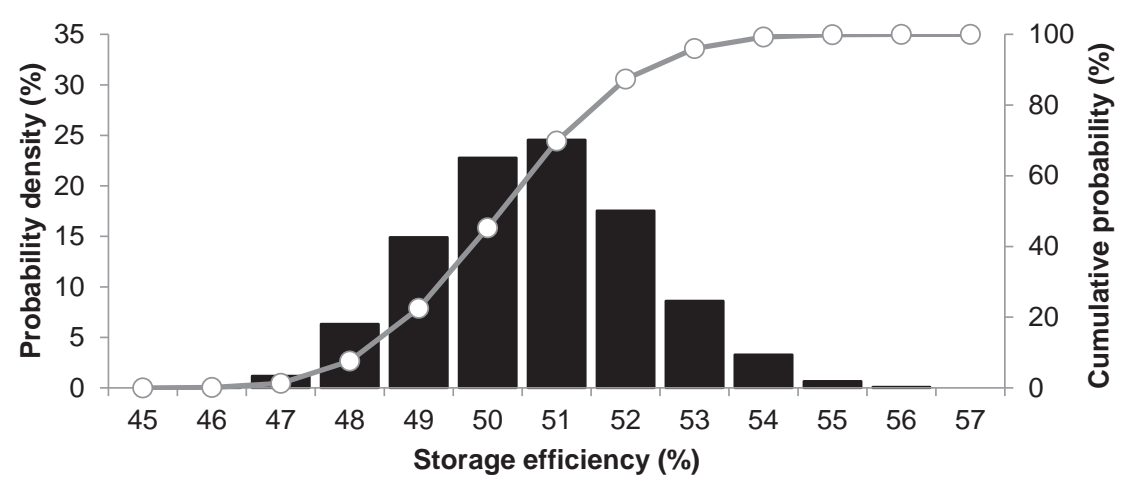

Probability density $\quad-0-$ Cumulative probability

Fig. 5 - Effect of uncertainty on storage efficiency.

has revealed that the statistical distribution of all these thermodynamic performance indicators is close to the normal distribution, what indicates a strong influence of the electrolyser and boiler efficiencies on the performance of the PtG process, as these input variables were represented using a normal distribution.

The storage efficiency, which characterises the amount of electricity from RES stored in the form of chemical energy of SNG, has been shown to fall between have the mean value of $50.2 \%$, with the figures for the 5 th and 95th percentile estimated to be 47.7 and $52.8 \%$. As the storage efficiency was shown to be directly dependent upon the electrolyser efficiency [7], which was assumed to have a standard deviation of $2 \%$, these results indicate the linear correlation between these input and output variables. Therefore, it is important to maintain high operating efficiency of the electrolyser throughout the lifetime of the PtG process, to avoid degenerating its energy storage capabilities.

The main subsystems of the PtG process operate at a high temperature, such as oxy-fuel boiler and methanators, enabling heat recovery for further utilisation and leading to an increase in the overall efficiency of the PtG process. The stochastic analysis indicated that the heat production efficiency (Fig. 6a), which is directly related to the oxy-fuel boiler efficiency that varied between 86 and $90 \%$, varies significantly between $41.8 \%$ (5th percentile) and $47.4 \%$ (95th percentile), with the mean value of $44.6 \%$. This indicates that per each unit of RES energy consumed by the PtG process, approximately 0.45 unit of heat will be produced in the oxy-fuel boiler, on average. On the other hand, variation in the heat recovery efficiency from the methanators was found not to vary to the same extent as the heat production efficiency (Fig. 6b). The stochastic analysis showed that under uncertain input, the heat recovery efficiency varied between $11.5 \%$ and $13.5 \%$, with the mean value equal to $12.4 \%$. This can be directly associated to relatively small variations in the methane content in SNG that was assumed to vary uniformly between 85 and 95\%vol. The stochastic analysis (Fig. 6c) have also indicated that the mean value of the overall efficiency of the PtG process under 


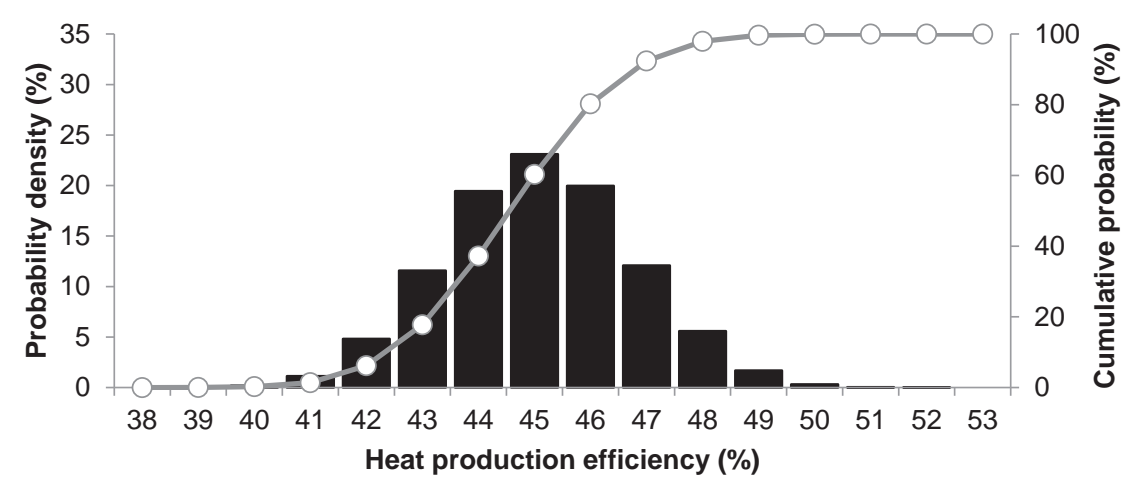

Probability density $\quad-0-$ Cumulative probability

a)

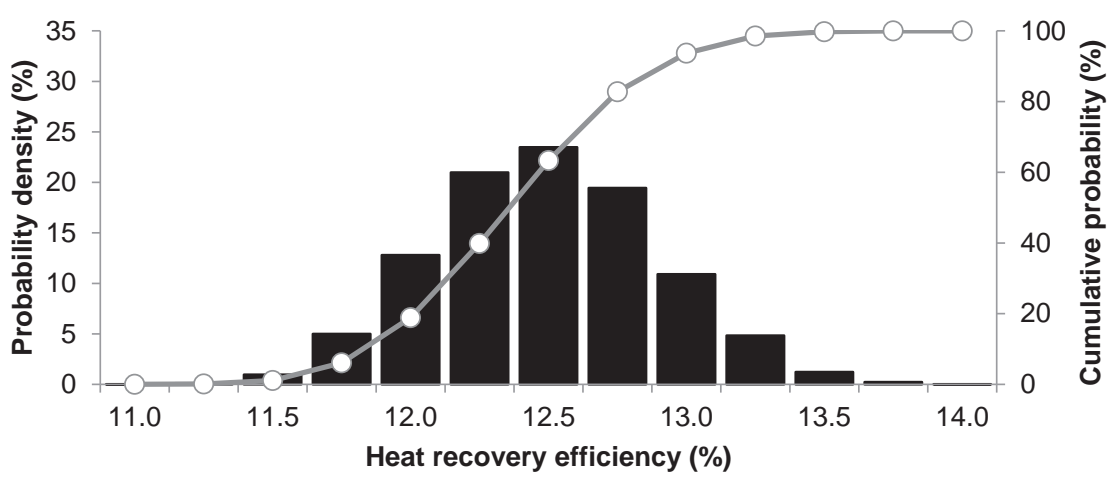

Probability density $\quad-\mathrm{O}-$ Cumulative probability

b)

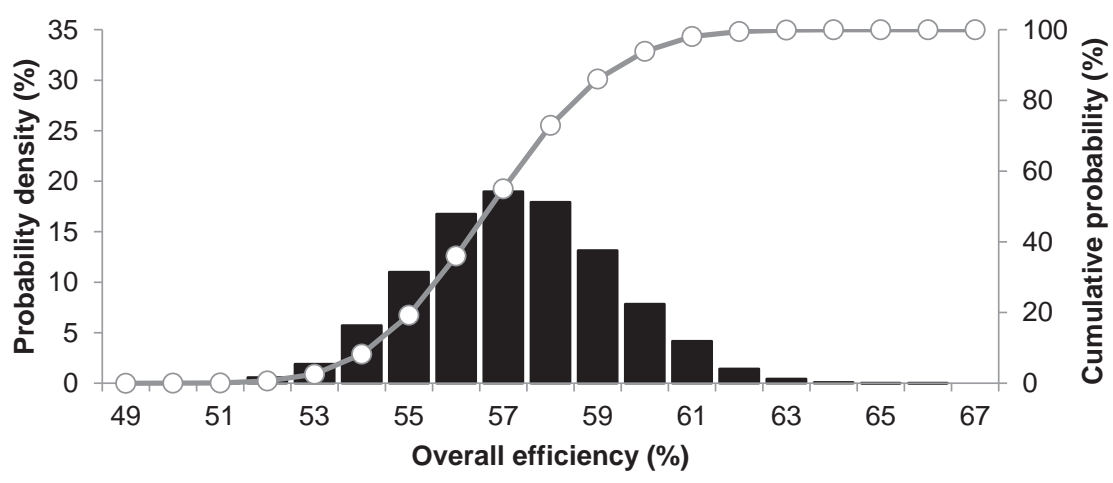

Probability density $\quad-\circ-$ Cumulative probability

c)

Fig. 6 - Effect of uncertainty on a) heat production, b) heat recovery, and c) overall efficiency of power-to-gas process.

uncertain input will be $56.7 \%$, and this key thermodynamic performance indicator is likely to vary between 53.5 (5th percentile) and $60.2 \%$ (95th percentile).

Overall, the stochastic analysis of the thermodynamic performance have revealed that for each unit of electricity consumed from RES, the PtG process will, on average, produce 0.502 units of chemical energy in SNG and 0.567 units of heat, the latter of which stem from both oxy-fuel boiler ( 78\%) and methanators ( 22\%). The total utilisation of electricity from RES, which accounts for the chemical energy in SNG and heat from methanators, would reach approximately $62.6 \%$. It has been also shown that the uncertainty in the input variables do not have a significant effect on the avoided $\mathrm{CO}_{2}$ per unit of heat production (Fig. 7), as this was shown to vary between 0.22 (5th percentile) and 0.24 (5th percentile) $\mathrm{tCO}_{2} / \mathrm{MW}_{\mathrm{el}} \mathrm{h}$, with the mean value of $0.23 \mathrm{tCO}_{2} / \mathrm{MW}_{\mathrm{el}} \mathrm{h}$.

\section{Economic performance}

This study assumes that the revenue associated with the heat sales must cover all operating and capital costs of the PtG process over the lifetime of the project. The stochastic 


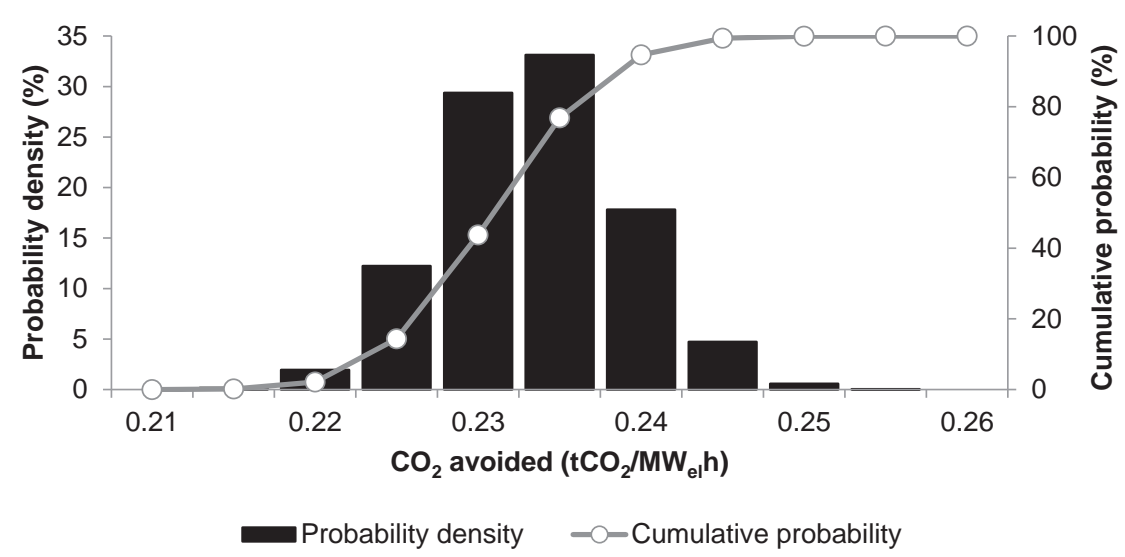

Fig. 7 - Effect of uncertainty on $\mathrm{CO}_{2}$ avoided.

analysis (Fig. 8a) indicated that under the economic conditions specified in Table 1 , the mean value of the discounted cash flows will be $-0.2 \mathrm{M} € / \mathrm{MW}_{\mathrm{el}}$, with the figures for the 5 th and 95th percentile estimated to be -0.42 and $0.08 \mathrm{M} € / \mathrm{MW}$ el, respectively. Importantly, the probability that the discounted cash flow is positive was estimated to be only $13.4 \%$, under the set of conditions provided in Table 1 . As a result, the net present value of the PtG process, which accounts for both capital investment and discounted cash flow, was estimated to have the mean value of $-1.7 \mathrm{M} € / \mathrm{MW}_{\mathrm{el}}$, and varied between

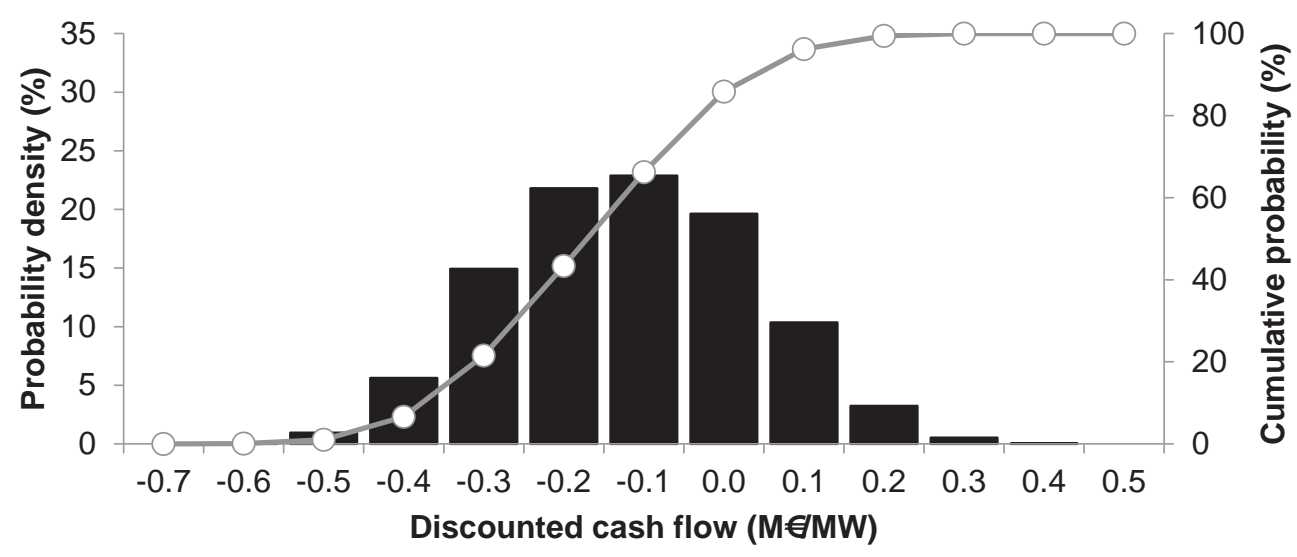

Probability density $\quad-\mathrm{O}-$ Cumulative probability

a)

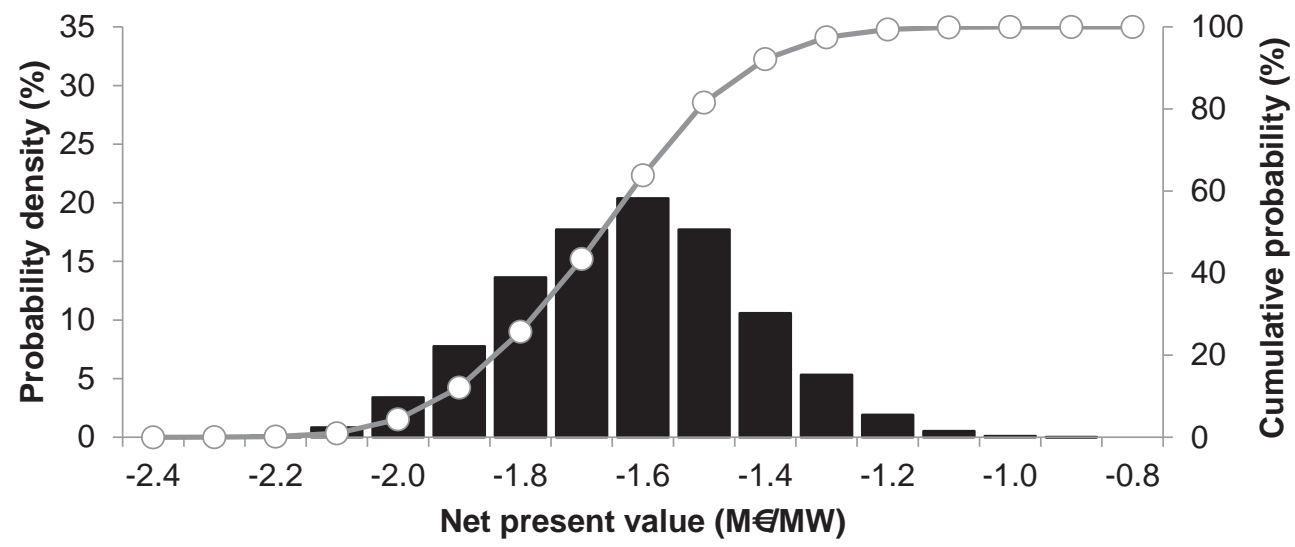

Probability density $\quad-\circ-$ Cumulative probability

b)

Fig. 8 - Effect of uncertainty on a) discounted cash flow and b) net present value. 


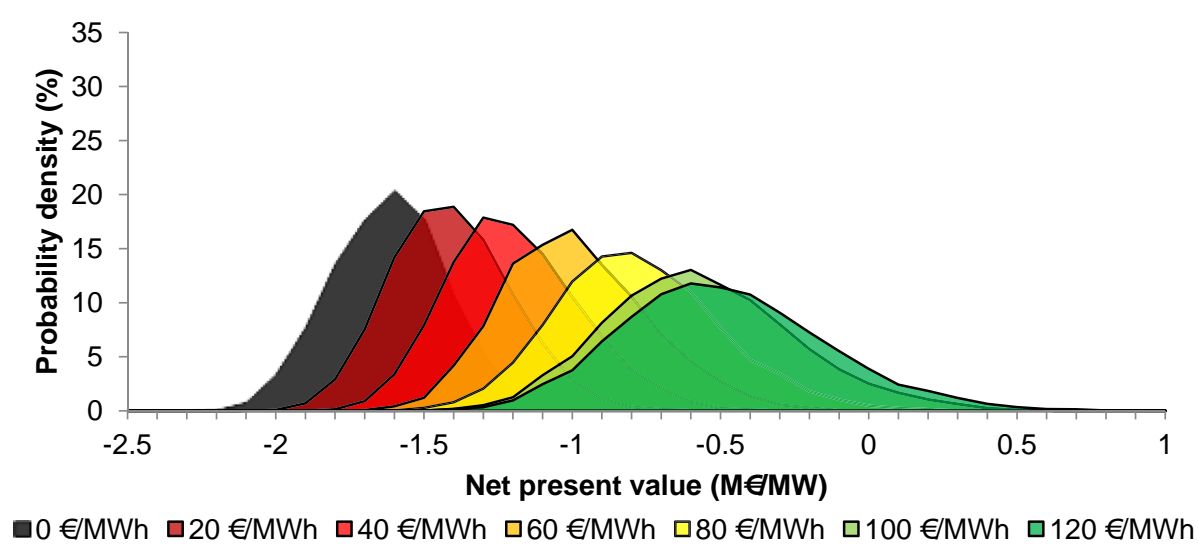

Fig. 9 - Effect of subsidy on net present value.

-2.0 (5th percentile) and $-1.4 \mathrm{M} € / \mathrm{MW}_{\mathrm{el}}$ (95th percentile). This indicates that the capital investment cannot be covered by the revenue from the heat sales alone.

A wide deployment of the PtG process will reduce the need for curtailment of RES, which is one of the key challenges for the energy systems with high level of variable RES penetration. This is because the RES operators need to be paid to reduce their power output to offset the loss in revenue [46]. Not only the PtG process has a potential to increase the utilisation of RES, but also it could reduce the cost of electricity. Therefore, the Governments need to provide incentives for investment in such technologies, for example in the form of subsidies, to make them more economically attractive. To assess the extent to which the governmental support is required to make the PtG process economically feasible, a sensitivity analysis (Fig. 9) that assumed that the governmental subsidy can vary between 0 and $120 € / \mathrm{MW}_{\text {th }} \mathrm{h}$, with respect to the overall amount of heat available in the PtG process, was performed.

The analysis revealed that the net present value can become positive only for the subsidy of $80 € / \mathrm{MW}_{\text {th }} \mathrm{h}$, but with the probability of $0.14 \%$. The probability of the positive net present value increases to $5.8 \%$ for the subsidy of 120 $€ / \mathrm{MW}_{\text {th }} \mathrm{h}$. Considering the mean value of the overall thermal efficiency of the PtG process of $56.7 \%$, this figure corresponds to $68 € / \mathrm{MW}_{\mathrm{el}} \mathrm{h}$, with respect to the electricity consumed by PtG process from RES. Such figure is close to the lower end of the range reported for the average wind farm constraint payments that varied between 70 and $280 € / \mathrm{MW}_{\mathrm{el}} \mathrm{h}$ between 2010 and 2018 [47]. Therefore, if similar subsidies to the ones for the wind operators become available, the PtG process could become economically feasible in the current economic environment.

\section{Conclusions}

One of the main challenges for the renewable energy development is the management of the fluctuations in production and how it is fitted with the demand requirements. For this reason, energy storage is essential in the deployment of this source of energy. Power-to-Gas (PtG) is a promising option of renewable energy storage that transforms energy surpluses into other energy carriers as SNG and heat. For the quantification of the energetic and economic variables of this system, deterministic analyses have been used. Nevertheless, this analysis does not take into account the uncertainty of the input variables and is very sensitive to the selection of specific assumptions.

This work has presented a novel stochastic approach for the thermodynamic and economic analysis of PtG-oxy-fuel under uncertainties of some input variables. In short, this kind of hybrid process is a Power-to-Heat system, with the advantages of a better storage functionality than Power-toHydrogen and the possibility of using conventional equipment for natural gas (cheaper equipment than for hydrogen, less operational complexity and lighter safety measures). The stochastic analysis has highlighted the stochastic results of main energy and economic variables of the system. It has also revealed that net present value and discounted cash flow are affected by the uncertainty in the input variables to the process and economic models.

The stochastic analysis of the thermodynamic performance has shown that the PtG process reaches on average an efficiency of $62.6 \%$ considering the RES energy input. Per each unit of RES energy consumed by the PtG process, approximately 0.45 unit of heat will be produced in the oxy-fuel boiler, on average. These values are aligned well with the deterministic results reported in the literature. Regarding the economic performance, the mean value of the discounted cash flows will be $-0.2 \mathrm{M} € / \mathrm{MW}_{\mathrm{el}}$, that is an unfeasible value. The probability that the discounted cash flow is positive was estimated to be only $13.4 \%$, under the set of conditions considered in the work. The net present value of the PtG process has a mean value of $-1.7 \mathrm{M} € / \mathrm{MW}_{\mathrm{el}}$. As a consequence, the capital investment cannot be covered by the revenue and saves.

With these results, the governmental support is required to make the PtG process economically feasible. The analysis revealed that the net present value can become positive with a subsidy of $120 € / \mathrm{MW}_{\text {th }} \mathrm{h}$, but with the probability of $5.8 \%$. This figure corresponds to $68 € / \mathrm{MW}_{\mathrm{el}} \mathrm{h}$, with respect to the electricity consumed by PtG process from RES, that is similar to other technologies in the current economic environment. This 
analysis would allow making more insightful decisions regarding economic feasibility assessment and further funding and/or subsidies to the renewable energy.

\section{Acknowledgments}

The work described in this paper is supported by the $\mathrm{R}+\mathrm{D}$ Spanish National Program from Ministerio de Economía y Competitividad, MINECO (Spanish Ministry of Economy and Competitiveness) and the European Regional Development Funds (European Commission), under project ENE2016-76850R. It is also supported by the UK Engineering and Physical Sciences Research Council, under project EP/P034594/1. Financial support for M.B. during his Ph.D. studies was cofunded by the Department of Industry and Innovation of Diputación General de Aragón, and by the European Social Fund. Campus Iberus is gratefully acknowledge for the mobility program support to L.M.R.

\section{Nomenclature}

$\begin{array}{ll}\text { Variables } \\ C & \text { price, } \mathrm{M} € / \mathrm{MWh} \\ \mathrm{h} & \text { annual PtG process operating time, hours } \\ \mathrm{i} & \text { discount rate, }- \\ \mathrm{LHV} & \text { lower heating value, } \mathrm{kJ} / \mathrm{kg} \\ \dot{m} & \text { mass flow, } \mathrm{kg} / \mathrm{s} \\ \mathrm{N} & \text { project lifetime, years } \\ \dot{Q} & \text { heat production, } \mathrm{kW} \\ \mathrm{R}_{0} & \text { capital investment per unit renewable electricity } \\ & \text { input, M€/MW } \mathrm{el} \\ R_{\mathrm{t}} & \text { net cash flow at year } \mathrm{t}, \mathrm{M} € / \mathrm{MW} \text { el } \\ t & \text { year, years } \\ \dot{W} & \text { electricity consumption, } \mathrm{kW} \\ \eta & \text { efficiency with respect to the electricity input from } \\ & \text { RES, }-\end{array}$

\section{Subscripts}

1 heat production in boiler

2 heat recovery in methanation stage

Elec electrolyser

Production production of heat in the oxy-fuel boiler

Q sales of heat

RE purchase of renewable electricity

Recovery recovery of heat from the methanation process

SNG synthetic natural gas

Storage storage of electricity in the form of methane

Thermal overall thermal production

\section{R E F E R E N C E S}

[1] European Parliament. Directive 2009/28/EC of the European Parliament and of the Council of 23 April 2009. 2009.

[2] European Commission. Proposal for a DIRECTIVE OF THE EUROPEAN PARLIAMENT AND OF THE COUNCIL on the promotion of the use of energy from renewable sources (recast). 2016. COM/2016/0767 final - 2016/0382 (COD).
[3] Aneke M, Wang M. Energy storage technologies and real life applications - a state of the art review. Appl Energy 2016;179:350-77. https://doi.org/10.1016/ j.apenergy.2016.06.097.

[4] Bailera M, Lisbona P. Energy storage in Spain: forecasting electricity excess and assessment of power-to-gas potential up to 2050. Energy 2018;143. https://doi.org/10.1016/ j.energy.2017.11.069.

[5] Lisbona P, Frate GF, Bailera M, Desideri U. Power-to-gas: analysis of potential decarbonization of Spanish electrical system in long-term prospective. Energy 2018;159:656-68. https://doi.org/10.1016/j.energy.2018.06.115.

[6] Götz M, Lefebvre J, Mörs F, McDaniel Koch A, Graf F, Bajohr S, et al. Renewable power-to-gas: a technological and economic review. Renew Energy 2016;85:1371-90.

[7] Bailera M, Lisbona P, Romeo LM. Power to gas-oxyfuel boiler hybrid systems. Int J Hydrogen Energy 2015;40. https:// doi.org/10.1016/j.ijhydene.2015.06.074.

[8] Sterner M. Bioenergy and renewable power methane in integrated $100 \%$ renewable energy systems. In: Limiting global warming by transforming energy systems, vol. 14; 2009.

[9] Wall T, Liu Y, Spero C, Elliott L, Khare S, Rathnam R, et al. An overview on oxyfuel coal combustion-State of the art research and technology development. Chem Eng Res Des 2009;87:1003-16. https://doi.org/10.1016/j.cherd.2009.02.005.

[10] Hu Y, Li X, Li H, Yan J. Peak and off-peak operations of the air separation unit in oxy-coal combustion power generation systems. Appl Energy 2013;112:747-54. https://doi.org/ 10.1016/j.apenergy.2012.12.001.

[11] Guilera J, Ramon Morante J, Andreu T. Economic viability of SNG production from power and CO2. Energy Convers Manag 2018;162:218-24. https://doi.org/10.1016/ j.enconman.2018.02.037.

[12] Kotowicz J, Węcel D, Jurczyk M. Analysis of component operation in power-to-gas-to-power installations. Appl Energy 2018;216:45-59. https://doi.org/10.1016/ j.apenergy.2018.02.050.

[13] Bailera M, Espatolero S, Lisbona P, Romeo LM. Power to gaselectrochemical industry hybrid systems: a case study. Appl Energy 2017;202. https://doi.org/10.1016/ j.apenergy.2017.05.177.

[14] Parra D, Zhang X, Bauer C, Patel MK. An integrated technoeconomic and life cycle environmental assessment of power-to-gas systems. Appl Energy 2017;193:440-54. https:// doi.org/10.1016/j.apenergy.2017.02.063.

[15] Sun G, Chen S, Wei Z, Chen S. Multi-period integrated natural gas and electric power system probabilistic optimal power flow incorporating power-to-gas units. J Mod Power Syst Clean Energy 2017;5:412-23. https://doi.org/10.1007/ s40565-017-0276-1.

[16] Ye J, Yuan R. Integrated natural gas, heat, and power dispatch considering wind power and power-to-gas. Sustainability 2017;9:602. https://doi.org/10.3390/su9040602.

[17] $\mathrm{Hu} \mathrm{M}$, Cho H. A probability constrained multi-objective optimization model for CCHP system operation decision support. Appl Energy 2014;116:230-42. https://doi.org/ 10.1016/j.apenergy.2013.11.065.

[18] Tzimas E. The cost of carbon capture and storage demonstration projects in Europe. 2009.

[19] Hanak DP, Kolios AJ, Biliyok C, Manovic V. Probabilistic performance assessment of a coal-fired power plant. Appl Energy 2015;139:350-64. https://doi.org/10.1016/ j.apenergy.2014.10.079.

[20] Heck N, Smith C, Hittinger E. A Monte Carlo approach to integrating uncertainty into the levelized cost of electricity. Electr J 2016;29:21-30. https://doi.org/10.1016/ j.tej.2016.04.001. 
[21] Geissmann T. A probabilistic approach to the computation of the levelized cost of electricity. Energy 2017;124:372-81. https://doi.org/10.1016/j.energy.2017.02.078.

[22] Hanak DP, Kolios AJ, Manovic V. Comparison of probabilistic performance of calcium looping and chemical solvent scrubbing retrofits for $\mathrm{CO} 2$ capture from coal-fired power plant. Appl Energy 2016;172:323-36. https://doi.org/10.1016/ j.apenergy.2016.03.102.

[23] Rubin ES, Rao AB. Uncertainties in $\mathrm{CO} 2$ capture and sequestration costs. In: Greenh Gas Control Technol - 6th Int Conf, II; 2003. p. 1119-24. https://doi.org/10.1016/B978008044276-1/50177-X.

[24] Hanak DP, Manovic V. Economic feasibility of calcium looping under uncertainty. Appl Energy 2017;208:691-702. https://doi.org/10.1016/j.apenergy.2017.09.078.

[25] ABB. Power Generation. Energy efficient design of Auxiliary systems in fossil-fuel power plants. Zurich, Switzerland; Wickliffe, OH, USA. 2009.

[26] Drbal L, Westra K, Boston P, editors. Power plant engineering. New York, NY, USA: Springer; 1996.

[27] Liptak BG, editor. Instrument engineers' handbook: process control and optimization. London, UK; New York, NY, USA; Washington, DC, USA: CRC-Press; 2005.

[28] Kumar R, Sharma A, Tewari P. Markov approach to evaluate the availability simulation model for power generation system in a thermal power plant. Int J Ind Eng Comput 2012;3:743-50.

[29] Oko E, Wang M, Zhang J. Neural network approach for predicting drum pressure and level in coal-fired subcritical power plant. Fuel 2015;151:139-45. https://doi.org/10.1016/ j.fuel.2015.01.091.

[30] Smrekar J, Assadi M, Fast M, Kuštrin I, De S. Development of artificial neural network model for a coal-fired boiler using real plant data. Energy 2009;34:144-52. https://doi.org/ 10.1016/j.energy.2008.10.010.

[31] Kalogirou SA. Applications of artificial neural-networks for energy systems. Appl Energy 2000;67:17-35. https://doi.org/ 10.1016/S0306-2619(00)00005-2.

[32] Romeo LM, Gareta R. Neural network for evaluating boiler behaviour. Appl Therm Eng 2006;26. https://doi.org/10.1016/ j.applthermaleng.2005.12.006.

[33] Bailera M, Lisbona P, Romeo LM, Espatolero S. Power to Gasbiomass oxycombustion hybrid system: energy integration and potential applications. Appl Energy 2016;167:221-9. https://doi.org/10.1016/j.apenergy.2015.10.014.

[34] Diéguez PM, Ursúa A, Sanchis P, Sopena C, Guelbenzu E, Gandía LM. Thermal performance of a commercial alkaline water electrolyzer: experimental study and mathematical modeling. Int J Hydrogen Energy 2008;33:7338-54. https:// doi.org/10.1016/j.ijhydene.2008.09.051.
[35] Sudiro M, Bertucco A. Synthetic Natural Gas (SNG) from coal and biomass: a survey of existing process technologies, open issues and perspectives. Nat. Gas Sciyo 2010:105-27. https:// doi.org/10.5772/9835.

[36] Wang F, Li H, Zhao J, Deng S, Yan J. Technical and economic analysis of integrating low-medium temperature solar energy into power plant. Energy Convers Manag 2016;112:459-69. https://doi.org/10.1016/ j.enconman.2016.01.037.

[37] Luz FC, Rocha MH, Lora EES, Venturini OJ, Andrade RV, Leme MMV, et al. Techno-economic analysis of municipal solid waste gasification for electricity generation in Brazil. Energy Convers Manag 2015;103:321-37. https://doi.org/ 10.1016/j.enconman.2015.06.074.

[38] Blanco H, Faaij A. A review at the role of storage in energy systems with a focus on Power to Gas and long-term storage. Renew Sustain Energy Rev 2018;81:1049-86. https://doi.org/ 10.1016/j.rser.2017.07.062.

[39] Lehner M, Tichler R, Koppe M. Power-to-gas : technology and business model. Springer; 2014.

[40] Choi SK, Grandhi RV, Canfield RA. Structural reliability under non-Gaussian stochastic behavior. Comput Struct 2004;82:1113-21.

[41] Kolios AJ, Casali D. Uncertainty quantification of pipe flow systems. In: Proc. 10th int. probabilistic work., Stuttgart, Gernabt; 2012.

[42] Kolios AJ, Quinio A, Anoniadis A, Brennan F. An approach of stochastic expansions for the reliability assessment of complex structures. In: Proc. 8th int. Probabilistic work; 2010. p. 223. Szczecin: 2010.

[43] Rönsch S, Schneider J, Matthischke S, Schlüter M, Götz M, Lefebvre J, et al. Review on methanation - from fundamentals to current projects. Fuel 2016;166:276-96.

[44] Trujillo-Baute E, del Río P, Mir-Artigues P. Analysing the impact of renewable energy regulation on retail electricity prices. Energy Pol 2018;114:153-64. https://doi.org/10.1016/ j.enpol.2017.11.042.

[45] Martinopoulos G, Papakostas KT, Papadopoulos AM. A comparative review of heating systems in EU countries, based on efficiency and fuel cost. Renew Sustain Energy Rev 2018;90:687-99. https://doi.org/10.1016/j.rser.2018.03.060.

[46] Renewable Energy Foundation. Notes on wind farm constraint payments. 2016. http://www.ref.org.uk/energydata/notes-on-wind-farm-constraint-payments. [Accessed 3 May 2018].

[47] Renewable Energy Foundation. Balancing mechanism wind farm constraint payments. 2018. www.ref.org.uk/constraints/ indexbymth.php? order=avgprice \&dir=asc\&start $=$. [Accessed 3 May 2018] 